\title{
PENGARUH LATIHAN CIRCUIT TRAINING INTENSITAS MODERAT DAN INTENSITAS EXHAUST TERHADAP TEKANAN DARAH DAN DENYUT NADI RECOVERY PADA SISWA EKSTRAKURIKULER FUTSAL DI SMK NEGERI 8 MALANG
}

\author{
Reza Sofa Elyasa \\ Saichudin \\ Rias Gesang Kinanti \\ Jurusan IImu Keolahragaan \\ Fakultas IImu Keolahragaan Universitas Negeri Malang \\ E-mail: rezasofa86@gmail.com
}

\begin{abstract}
Sports is an activity that has an impact on improving health, physical, physiological, and psychological conditions. Sports are also related to the heart and blood vessels, because the heart is a vital organ that supplies blood throughout the body. The purpose of this study was to determine whether there was influence of moderate intensity circuit training and sexhaust intensity. The research design used was a Static Group Pretest-Posttest Design. The research subjects were 30 students of futsal extracurricular at SMKN 8 Malang, who were divided into groups of moderate circuit training training in 15 students and groups of 15 students in the training circuit for intenstas exhaust. The results of the SPSS Wilcoxon Signed Ranks Test analysis in getting the calculation of different tests between groups using the Wilcoxon Signed Ranks Test in the Test Statistics box are seen as Z -3,873 with Asymp. Sig. (2-tailed) of 0.00 or smaller than 0.05 , which means that $\mathrm{HO}$ is rejected and there is influence, so it was decided that there were differences in heart rate levels before and after circuit training with moderate intensity and exhaust intensity, it could be concluded that there was an effect of giving circuit training for the blood pressure work system for futsal extracurricular students at SMKN 8 Malang.

Keywords:circuit training, blood pressure, exercise.
\end{abstract}

\begin{abstract}
Abstrak: Olahraga merupakan kegiatan yang berdampak terhadap peningkatan kesehatan, kondisi fisik, fisiologis, dan juga psikologis. Olahraga juga berkaitan dengan jantung dan pembuluh darah, karena jantung merupakan organ vital yang memasok kebutuhan darah di seluruh tubuh.Tujuan dari penelitian ini adalah untuk mengetahui apakah ada pengaruh circuit training intensitas moderat dan intensita sexhaust. Rancangan penelitian yang digunakan berupa rancangan kelompok pembanding prates-pascates berpasangan (Static Group Pretest-Posttest Design). Subjek penelitian ada 30 siswa ekstrakulikuler futsal SMKN 8 Malang, yang dibagi menjadi kelompok latihan circuit training intenstas moderat 15 siswa dan kelompok latihan circuit training intenstas exhaust 15 siswa. Hasil analisis SPSS Wilcoxon Signed Ranks Test di dapatkan perhitungan uji beda antar kelompok menggunakan Wilcoxon Signed Ranks Test pada kotak Test Statistics terlihat nilai Z -3,873 dengan Asymp. Sig. (2-tailed) sebesar 0,00 atau lebih kecil dari 0,05 yang berarti HO ditolak dan adanya pengaruh, sehingga diputuskan ada perbedaan tingkat heart rate sebelum dan sesudah latihan circuit training dengan intensitas moderat dan intensits exhaust,dapat disimpulkan bahwa ada pengaruh pemberian latihan circuit training terhadap sistem kerja tekanan darah siswa ekstrakulikuler futsal SMKN 8 Malang.
\end{abstract}

Kata kunci: circuit training, tekanan darah, olahraga. 
Olahraga merupakan kegiatan yang berdampak terhadap peningkatan kesehatan, kondisi fisik, fisiologis, dan juga psikologis. Olahraga juga berkaitan dengan jantung dan pembuluh darah, karena dapat dipahami jantung merupakan organ vital yang memasok kebutuhan darah di seluruh tubuh. Dengan meningkatnya aktivitas fisik seseorang maka kebutuhan darah yang mengandung oksigen akan semakin besar. Kebutuhan ini akan dipenuhi oleh jantung dengan meningkatkan aliran darahnya (Widiyanto, 2008:28). Tekanan darah dipengaruhi oleh aktivitas fisik, akan lebih tinggi pada saat melakukan aktivitas dan lebih rendah ketika beristirahat (Novita, 2009:185). Tekanan darah juga merupakan faktor yang amat penting pada sistem sirkulasi, peningkatan atau penurunan tekanan darah akan mempengaruhi homeostatsis di dalam tubuh (Anggara dkk,2013:5). Namun masyarakat pada umumnya belum banyak mengetahui intensitas olahraga yang sesuai untuk dilakukan agar tidak mengganggu homeostatis di dalam tubuh. Padahal semakin berat intensitas olahraga akan mengakibatkan tekanan darah semakin meningkat, latihan yang berat dapat menjadi stressor yang dapat mengganggu homeo-stasis tubuh (Sugiharto, 2012:54).

Tekanan darah merupakan salah satu dari tanda vital penting selain denyu tnadi, frekuensi nafas dan suhu. Tanda vital ini mencerminkan aspek dasar kesehatan seseorang, bahkan juga kemampuan seseorang untuk bertahan hidup. Pada dewasa muda tekanan sistolik adalah $120 \mathrm{mmHg}$, dan tekanan diastolic adalah $80 \mathrm{mmHg}$. Perbedaan antara kedua tekanan disebut tekanan nadi, yaitu $40 \mathrm{mmHg}$. Tekanan darah dipertahankan dalam batas-batas yang adekuat dengan cara interaksi kompleks antara mekanisme neuronal dan hormonal dimana adekuasi tekanan darah sangat diperlukan untuk perfusi jaringan dan mendorong berlangsungnya sirkulasi darah (Purba, 2006:9). Agar olahraga tidak mengganggu homeostatis dalam tubuh perlu dilakukan latihan yang terstruktur, maka dari itu perlu dilakukan program latihan secara cermat, sistematis, teratur dan selalu meningkat serta mengikuti prinsip-prinsip dan metode latihan yang akurat. Program pelatihan yang cocok diberikan yaitu pelatihan circuit training (Hariyanti dkk, 2013).

Latihan circuit training dapat meningkatkan daya tahan kardiovaskular, dengan adanya pelatihan ini proses penyaluran dan kembalinya darah ke jantung semakin lancar, sehingga mengakibatkan kesempurnaan proses metabolism dalam tubuh. Fungsi kardiovaskular dalam olahraga adalah mengangkut oksigen 
dan nutrisi lain ke otot. Aliran darah menuju otot meningkat secara dramatis selama latihan. Hampir separuh dari kenaikan aliran ini merupakan akibat vasodilatasi intramuskular yang disebabkan oleh pengaruh langsung kenaikan metabolism otot (Sarifin, 2011:8). Sekresi epinefrin yang terjadi akibat kebutuhan metabolism otot berbengaruh pada meningkatnya kontraksi otot-otot rangka maupun otot jantung. Dan meningkatnya kontraksi otot jantung akan menyebabkan meningkatnya volume darah sedenyutan (stroke vulume=SV) (Purba, 2006:11). Dari hasil penelitian Almy dan Sukadiyanto (2014:59) circuit training berpengaruh terhadap daya tahan kardiovaskuler, dan dapat menguatkan otot-otot pernafasan hal tersebut memberikan manfaat yang besar terhadap pemeliharaan kebugaran jantung dan paru-paru. Serta dalam circuit training melibatkan tiga variabel sekaligus yaitu : intensitas, repetisi, dan durasi. Dalam circuit training ini variasi latihan dapat diatur, menghemat waktu dan mentoleransi perbedaan individu. Sehingga jantung seseorang yang melakukan latihan secara rutin berukuran lebih besar. Dengan demikian volume darah sedenyut (stroke volume=SV) akan meningkat dan untuk memenuhi kebutuhan oksigen maupun membuang karbondioksida, jantung tidak perlu memompa dengan frekuensi yang tinggi. Oleh karena itu atlet yang terlatih dalam daya tahan aerobic denyut nadi minimalnya akan di bawah 60 kali per menit, bahkan lebih rendah dari 50 kali per menit (Smith, 2011:89).

Berdasarkan uraian diatas maka peneliti melakukan penelitian dengan judul "Pengaruh Latihan Circuit Training Intensitas Moderat dan Intensitas Exhaust terhadap Tekanan Darah dan Denyut Nadi Recovery pada siswa ekstrakulikuler futsal di SMK Negeri 8 Malang".

Berdasarkan paparan di atas, maka penulis mengambil rumusan masalah sebagai berikut: (1) apakah latihan circuit training dengan intensitas moderat berpengaruh terhadap tekanan darah denyut nadi recovery, (2) apakah latihan circuit training dengan intensitas exhaust berpengaruh terhadap tekanan darah denyut nadi recovery, (3) apakah ada perbedaan pengaruh latihan circuit training dengan intensitas moderat dan intensitas exhaust terhadap tekanan darah denyut nadi recovery. Berdasarkan rumusan masalah yang dipaparkan maka hipotesis dari penelitian ini adalah: (1) latihan circuit training dengan intensitas moderat mempengaruhi tekanan darah denyut nadi recovery, (2) latihan circuit training dengan intensitas exhaust mempengaruhi tekanan darah denyut nadi recovery, (3) terdapat perbedaan pengaruh dari latihan circuit training dengan 
intensitas moderat dan intensitas exhaust terhadap tekanan darah denyut nadi recovery.

\section{METODE}

Penelitian yang digunakan adalah metode penelitian eksperimental semu (Pre-Experimental). Dikatakan eksperimen semu karena masih terdapat variabel dari luar yang dapat mempengaruhinya seperti aktivitas fisik yang sering dilakukan sehari-hari yang tidak dapat dikontrol oleh peneliti, dalam hal ini peserta ekstrakurikuler masih ada pelajaran pendidikan jasmani.Desain atau rancangan menggunakan rancangan kelompok pembanding prates-pascates berpasangan (Static Group Pretest-Posttest Design). Desain Static Group Pretest-Posttest Design dipilih karena untuk membandingkan pretest dan posttest setelah diberi perlakuan (Sukmadinata, 2013:209).

Untuk mengetahui tekanan darah awal dilakukan Pretest terlebih dahulu. Setelah perlakuan dilakukan posttest untuk mengetahui akibat dari perlakuan tersebut. Secara skematis dapat digambarkan sebagai berikut:

S. Latihan circuit training (intensitas moderat) $\longrightarrow \mathbf{P}_{\mathbf{1}} \longrightarrow \mathbf{X} \longrightarrow \mathbf{P}_{\mathbf{2}}$

S. Latihan circuit training (intensitas exhaust) $\longrightarrow \mathbf{P}_{1} \longrightarrow \mathbf{X} \longrightarrow \mathbf{P}_{2}$

\section{Gambar 3.1 Skema Rancangan Penelitian}

(Sumber: Sukmadinata, 2013:209)

\section{Keterangan:}

S : Subyek Penelitian

$\mathrm{P}_{1}$ : Pretest pada kedua kelompok eksperimen

$\mathrm{X}$ : Treatment atau perlakuan yang diberikan

$\mathrm{P}_{2} \quad$ : Posttest pada kedua kelompok eksperimen

\section{Populasi dan Sampel Penelitian}

Penelitian harus ada unsur subjek atau objek penelitian yang menjadi sasaran penelitia. Objek dan subjek penelitian berkaitan dan merupakan bagian dari populasi.Populasi dalam penelitian ini adalah peserta ekstrakurikuler futsal di SMK Negeri 8 Malang dengan jumlah siswa laki-laki 35 orang yang telah mengikuti pelatihan selama 2 bulan. Karena latihan selama 2 bulan sudah sesuai dengan adaptasi fisiologis tubuh terhadap pelatihan (Nala, 1998: 2).

\section{Instrumen Penelitian}

Instrumen penelitian adalah alat ukur yang digunakan untuk mengumpulkan data dalam penelitian (Sugiyono, 2014: 102). Instrumen yang 
digunakan untuk mengambil data adalah: (1) instrumen latihan: (cone) digunakan untuk menandai setiap pos pada sistem latihan circuit training, heart rate, sphygmomanometer dikenal juga dengan tensimeter, stopwatch merk casio yang mempunyai batas koreksi ketelitian 0,01 detik, peluit dolphin, alat tulis (bolpoin, booknote, dan pensil), (2) instrumen pengukuran:alat ukur yang digunakan untuk mengumpulkan data adalah harvard step test karena sudah memiliki tingkat (validitas) dalam menentukan daya tahan jantung pada konsep kardiovaskuer yang meliputi tekanan darah, denyut jantung, aliran darah dan curah jantung. Adapun alat yang dibutuhkan adalah: peluit, serbuk kapur (magnesium), alattulis (bolpoin, buku, dan pensil), form penilaian dan nama-nama yang diteliti, timbangan berat badan merk camry, stopwatch merk casio yang mempunyai batas koreksi ketelitian 0,01 detik, Balok kotak dengan tinggi $45 \mathrm{~cm}$.

\section{Waktu dan Tempat Penelitian}

Penelitian dilaksanakan selama 24 kali pertemuan dalam 3 (tiga) kali pertemuan per minggu. Pemberian perlakuan atau treatment selama 8 minggu sudah sesuai dengan fisiologis tubuh terhadap latihan. Lama suatu pelatihan sehingga diperoleh hasil yang konstan, karena tubuh telah beradaptasi dengan pelatihan tersebut tercapai dalam waktu 8 minggu (Nala, 1998: 2). Tempat penelitian dilakukan di lapangan futsal SMK Negeri 8 Malang.

\section{Pengumpulan Data}

Pengumpulan data merupakan proses mengidentifikasi dan mengoleksi informasi yang dilakukan oleh peneliti, sesuai dengan tujuan penelitian (Winarno, 2013: 103). Data diperoleh dari hasil pretest dan posttest. Prosedurnya yang akan diterapkan adalah: (1) tahap persiapan: observasi lapangan atau tempat yang akan digunakan, pengurusan surat ijin penelitian, menentukan populasi dan sampel, menyusun instrumen penelitian, menyiapkan fasilitas dan alat tes yang akan digunakan, menyiapkan catatan untuk merekap hasil penelitian, membuat surat pernyataan siswa peserta ekstrakurikuler untuk dijadikan objek penelitian, (2) pelaksanaan pretest: pelaksanaan harvard step test dengan naik turun balok selama 5 menit untuk mengetahui daya tahan kerja jantung dan pernapasan adalah sebagai berikut:atlet siap berdiri di belakang balok, pada hitungan satu, salah satu kaki naik ke atas balok sampai lutut lurus, pada hitungan dua, kaki yang lain naik ke atas bangku hingga kedua kaki tepat berada di atas balok, pada hitungan tiga, kaki yang pertama dinaikkan ke bangku tadi, diturunkan ke posisi semula di bawah, pada hitungan empat, kaki yang lain yang masih berada di atas 
bangku diturunkan sehingga kedua kaki tepatnya berada di bawah (di posisi semula). Demikian dilakukan terus sampai waktu yang ditentukan berakhir, (3) tahap pelaksanaan perlakuan: peserta diberi penjelasan dan pengarahan di awal pertemuan tentang treatment yang akan dilaksanakan, setiap akan melakukan treatment peserta terlebih dahulu melakukan pemanasan selama 15 menit, pada pelaksanaan latihan dilakukan selama 24 kali pertemuan, dalam setiap pertemuan akan diberikan intensitas, frekuensi, time dan type latihan yang akan meningkat setiap minggunya dengan prinsip overload, (4) pelaksanaan posttest: pelaksananan posttest dilakukan setelah seluruh program latihan selesai. Pelaksanaan posttest sama dengan pelaksanaan pretest. Data posttest diperoleh dari Harvard step test dan pengukuran tekanan darah.

\section{Analisis Data}

Jenis data yang akan dikumpulkan dalam penelitian ini adalah hasil Harvard step test dan tekanan darah. Kemudian hasil tes tersebut akan dicatat dan dihitung menggunakan teknik statistik deskriptif dan dianalisis dengan bantuan program komputer SPSS (Statistical Program For Social Science) 22.0. Analisis data yang dilakukan: (1) uji normalitas data: untuk menentukan normal tidaknya distribusi data adalah membandingkan taraf signifikansi perhitungan data dengan taraf $5 \%$. Jika taraf signifikansi dalam uji statistik lebih besar dari 0.05 maka dinyatakan berdistribusi normal, (2) uji homogenitas: Dalam penelitian ini digunakan lavene's test. Apabila nilai statistik lebih besar dari 0.05 maka data memiliki varian yang homogen, (3) uji hipotesis: untuk mengetahui besarnya perbedaan pengaruh perlakuan terhadap peningkatan variabel terikat sebelum dan setelah perlakuan antar kelompok digunakan analisis statistik non parmetrik, yaitu dengan Wilcoxon Signed Rank Test dengan p-value (sig)=0,05.

\section{HASIL DAN PEMBAHASAN}

Berdasarkan hasil harvard test yang dilakukan pada kelompok latihan eksperimen, diketahui latihan ini ada pengaruh yang signifikan terhadap peningkatan sistem kerja kardiovaskuler pada siswa ekstrakuilikuler futsal SMKN 8 Malang. Menurut Wilmore and Costill (2005), makin tepat ambang rangsang suatu program latihan endurance terhadap peningkatan kekuatan otot jantung, makin baik pula akibat latihan tersebut terhadap efisiensi kerja jantung. Sebagaimana para ahli fisiologi mengemukakan, bahwa otot jantung adalah 
sama dengan otot seran lintang lain, otot ini akan bertambah besar dan kuat apabila mendapat tahanan yang cukup berat dari suatu latihan.

Dari perhitungan Wilcoxon Signed Ranks Test pada kotak Test Statistics terlihat nilai Z -3,873 dengan A symp. Sig. (2-tailed) sebesar 0,00 atau lebih kecil dari 0,05 sehingga diputuskan ada perbedaan pengaruh latihan circuit training sebelum dan sesudah latihan.

Dapat disimpulkan bahwa latihan circuit training intensitas exhaust lebih berpengaruh banyak terhadap peningkatan denyut nadi pemulihan (recovery heart rate), daripada latihan circuit training intensitas moderat.

Sistem kerja kardiovaskuler merupakan hal yang sangat diperhitungkan pada cabang olahraga yang bersifat endurance. Dalam tingkat latihan submaksimal, dan berlangsung secara stabil, denyut jantung meningkat cepat untuk selanjutnya stabil setiap menitnya. Keadaan stabil seperti ini disebut "Steady State Heart Rate". Yaitu suatu keadaan denyut jantung tidak lagi bertambah cepat oleh pacuan yang timbul karena latihan tersebut. Makin tepat ambang rangsang suatu program latihan endurance terhadap peningkatan kekuatan otot jantung, makin baik pula akibat latihan tersebut terhadap efisiensi kerja jantung. Sebagaimana para ahli fisiologi mengemukakan, bahwa otot jantung adalah sama dengan otot seran lintan glain, otot ini akan bertambah besar (Wilmore and Costill, 2005).

Permainan futsal membutuhkan kemampuan daya tahan aerobik yang baik, ketika berlatih frekuensi denyut jantung akan meningkat. Kenaikan frekuensi Program pelatihan untuk meningkatkan $\mathrm{VO}_{2}$ max harus dapat dilakukan secara cermat, sistematis, teratur dan selalu meningkat, mengikuti prinsip-prinsip serta metode latihan yang akurat agar tercapai tujuan yang diharapkan. Alternatif pelatihan yang digunakan dalam penelitian ini adalah circuit training. Circuit training merupakan suatu sistem latihan yang dapat memperbaiki secara serempak fitness keseluruhan dari tubuh, yaitu unsur-unsur power, daya tahan, kekuatan, kelincahan, kecepatan, dan komponen kondisi fisik lainya (Kardjono, 2008:39).

Circuit training dalam penelitian ini menggunakan 6 pos. Berikut jenis latihan yang diberikan kepada kelompok eksperimen. (1) Pos 1; skipping/lompat tali (mahasiswa melakukan lompatan menggunakan tali yang disediakan), (2) Pos 2; shutlle run (mahasiswa melakukan lari bolak-balik dengan menyentuh garis batas yang telah diberikan), (3) Pos 3; sit up (mahasiswa dari posisi tidur 
kaki ditarik dan ditekuk, tangan dibelakang kepala kemudian siku-siku secara bergantian menyentuh lutut), (4) Pos 4; naik turun bangku (mahasiswa berada di depan bangku kemudian meloncat di atas bangku dengan satu kaki lalu secara bergantian meletakan kaki di atas bangku selanjutnya turun dari atas bangku dengan kaki yang bergantian, (5) Pos 5; lompat kijang (mahasiswa berdiri tegak kemudian meloncat-loncat setinggi mungkin seiring dengan lutut yang ditekuk menyentuh dada, dilakukan berturut-turut), (6) Pos 6; squat trush (mahasiswa berdiri kemudian melompat keatas langsung jongkok, taruh lengan di lantai, lemparkan kaki lurus kebelakang, jongkok kembali dan melompat).

Menurut Sajoto (1995:83) bahwa "ada dua program circuit training, yang pertama bahwa jumlah stasiun adalah 8 tempat. Satu stasiun diselesaikan dalam waktu 45 detik, dan dengan repetisi antara 15-20 kali, sedang waktu istirahat tiap stasiun adalah 1 menit atau kurang. Rancangan kedua dinyatakan bahwa jumlah stasiun antara 6-15 tempat". Satu stasiun diselesaikan dalam waktu 30 detik, dan satu sirkuit diselesaikan antara 5-20 menit, dengan waktu istirahat tiap stasiun adalah 15-20 detik.

Dalam penelitian sebelumnya menurut Wilmore and Costill (2005)“ bahwa denyut jantung adalah parameter yang sederhana dan cukup informatif, untuk mengukur tinggi rendahnya aktivitas tubuh seseorang. Denyut jantung seseorang yang normal, dalam arti tidak mengalami kelainan, rata-rata adala hantara 60100 kali tiap menit. Sedang denyut orang-orang yang terlatih, lebih-lebih atlet yang menggunakan endurance tinggi, seperti atlet 13 pelari jarak jauh, denyut jantungnya waktu istirahat dapat mencapai tingkat yang paling rendah, yaitu antara 28-40 kali setia pmenit. Dalam tingkat latihan submaksimal, dan berlangsung secara stabil, denyut jantung meningkat cepat untuk selanjutnya stabil setiap menitnya. Keadaan stabil seperti ini disebut "Steady State Heart Rate". Yaitu suatu keadaan denyut jantung tidak lagi bertambah cepat oleh pacuan yang timbul karena latihan tersebut. Makin tepat ambang rangsang suatu program latihan endurance terhadap peningkatan kekuatan otot jantung, makin baik pula akibat latihan tersebut terhadap efisiensi kerja jantung".

\section{SIMPULAN}

Berdasarkan hasil analisis data, diartikan bahwa latihan circuit training intensitas moderat tidak terdapat pengaruh yang signifikan terhadap tekanan darah pada siswa ekstrakulikuer futsal SMKN 8 Malang, yang telah diuraikan 
pada bab sebelumnya dan dibuktikan dengan hasil uji Wilcoxon Signed Ranks Test.

Berdasarkan hasil analisis data, diartikan bahwa latihan circuit training intensitas exhaust memberikan pengaruh yang signifikan terhadap tekanan darah pada siswa ekstrakulikuer futsal SMKN 8 Malang, yang telah diuraikan pada bab sebelumnya dan dibuktikan dengan hasil uji Wilcoxon Signed Ranks Test yang signifikan.

Maka dapat disimpulkan bahwa terdapat perbedaan pengaruh antara latihan circuit traning intensitas moderat dan intensitas exhaust. Dapat diketahui bahwa latihan circuit training intensitas exhaust dapat memberikan dampak lebih signifikan terhadap tekanan darah dibandingkan dengan latihan intensitas moderat pada siswa ekstrakulikuler futsal SMKN 8 Malang yang dibuktikan dengan hasil uji Wilcoxon Signed Ranks Test yang signifikan.

\section{Saran}

Berdasarkan hasil kesimpulan yang sudah dipaparkan maka saran sebagai berikut: (1) untuk para pemain futsal jika ingin meningkatkan kemampuan daya tahan kardiovaskuler tekanan darah dapat menggunakan circuit training intensitas exhaust, disarankan juga agar lebih memperhatikan prinsip-prinsi platihan pada saat menjalani latihan, (2) bagi peneliti selanjutnya, penelitian ini dapat dijadikan sebagai bahan masukan maupun perbandingan, jika peneliti selanjutnya ingin mengangkat masalah yang sejenis dalam rangka pengembangan ilmu dalam bidang keolahragaan dan agar dapat mempertimbangkan berbagai kekurangan atau keterbatasan dalam melaksanakan atau melakukan penelitian ini, tujuannya demi kemanfaatan hasil dari penelitian yang sudah dilaksanakan, (3) bagi Fakultas IImu Keolahragaan, penelitian ini bermanfaat sebagai bahan masukan dalam menyusun program latihan atau strategi latihan dalam olahraga yang mampu meningkatkan kemampuan terutama pada daya tahan dikalangan para atlet atau para olahragawan.

\section{DAFTAR RUJUKAN}

Anggara Febby Haendra D, Prayitno Nanang. 2013. Faktor-Faktor Yang Berhubungan Dengan Tekanan Darah Di Puskesmas Telaga Murni, Cikarang Barat Tahun 2012, Jurnal IImiah Kesehatan, 5 (1): 20-25

Kardjono. 2008. Modul Pembinaan Kondisi Fisik. Bandung: Universitas Pendidikan Indonesia. 
Nala. 1998. Prinsip Pelatihan Fisik Olahraga. Denpasar: Pascasarjana Fisiologi Olahraga Universitas Udayana

Purba, A. 2006. Kardiovaskular dan Faal Olahraga. Bagian IImu Faal/Faal Olah Raga Fakultas Kedokteran Universitas Padjadjaran Bandung. 8-13.

Samsudin. 2005. Pembelajaran Motorik di Taman Kanak-Kanak. Jakarta : Prenada Media Group.

Sarifin. 2011. Dampak Faall Dari Program Pelatihan (Exercise Program) Pada Orang Dewasa. Jurnal ILARA, I I (2): 8 - 1

Smith, D.L \&Fernhall, B. 2011. Advanced Cardiovascular Exercise Physiologi.USA: Human Kinetics.

Sugiharto. 2012. Fisioneurohormonal Pada Stresor Olahraga. Malang, Jurnal Sains Psikologi, 2 (2): 54-66.

Sugiyono. 2014. Metode Penelitian Kuantitatif, Kualitatif, dan R\&D. Bandung: Penerbit. Alfabeta.

Sukadiyanto dan Dangsina, M. 2011. Pengantar Teori dan Metodologi Melatih Fisik. Bandung: CV. Lubuk Agung.

Sukmadinata, N.S. 2013, Metode Penelitian Pendidikan. Bandung: PT REMAJA ROSDAKARYA.

Widiyanto. 2008. Respon Kardiovaskuler Akibat Latihan. Medikora, 4 (1): 24-46

Wilmore, J. H. \& Costill. 2005. Athletic Training and Psysical Fitness. Boston, Sidney : Allyn and Bacon.

Wilmore, J. H. \& Costill. 2005. Training For Sport and Activity. Win C. Brown Publisher, Bubuque, Lowa. 